\title{
Decreased Gait and Function in Duchenne Muscular Dystrophy
}

\author{
Cristina Iwabe-Marchese ${ }^{1}{ }^{*}$, Aline Fávaro ${ }^{2}$, Lívia Cocato Luiz ${ }^{1}$ \\ ${ }^{1}$ Neuromuscular Outcome, University State of Campinas-UNICAMP, Campinas, Brazil \\ ${ }^{2}$ Child Neurology Rehabilitation Outcome-UNICAMP, Campinas, Brazil \\ Email: ${ }^{*}$ crisiwabe@hotmail.com, favaro.aline@terra.com.br, liviacocato@gmail.com
}

Received 22 June 2014; revised 26 July 2014; accepted 8 August 2014

Copyright (C) 2014 by authors and Scientific Research Publishing Inc.

This work is licensed under the Creative Commons Attribution International License (CC BY). http://creativecommons.org/licenses/by/4.0/

(c) (7) Open Access

\section{Abstract}

Duchenne muscular dystrophy (DMD) is a genetic disorder linked to chromosome Xp21, due to absence of dystrophin production. It is clinically characterized by progressive muscle weakness, fatigue, and development of joint contractures that compromise general motor functionality, mainly the gait. Objective: To characterize the motor function and decrease gait in children with DMD using the Portuguese version of the Motor Function Measure scale (MFM-P). Methods: A review of medical records including chronological age and scores from MFM-P of children with a DMD who attended at the Neuromuscular Diseases Clinic at Campinas State University (UNICAMP), Brazil was performed in this study. A total of 36 medical records of male patients with confirmed clinical diagnosis of DMD, ambulatory or not, regardless of age; excluding those with other associated diseases or other types of muscular dystrophies were selected. Data were analyzed using Kolmogorov-Smirnov and Spearman correlation statistical tests. Results: Analysis of all data collected showed that $75 \%$ of our sample had D1 scores lower than $41.02 \%$. There was a linear relationship between the scores of D2 and D3, but no association between D2 and D1 scores was noted. D1 score was between $40 \%$ and $80 \%$ in those patients presenting D2 scores between $80 \%$ and $100 \%$. In all cases patients with low total score presented a greater risk for loss of gait and their functionality. Conclusion: The standing posture and the postural transfers were the worst activities observed in children with DMD, with positive correlation between proximal and distal motor function. Even with high scores according MFM-P in proximal function, the children showed strong predictors for loss of gait.

\section{Keywords}

Gait, Muscular Dystrophy, Duchenne, Functionality, Motor Function Measure Scale

\footnotetext{
${ }^{*}$ Corresponding author.
} 


\section{Introduction}

According to Fernandes et al. [1] Duchenne muscular dystrophy (DMD) is a neuromuscular disease caused by a genetic disorder linked to the $\mathrm{X}$ chromosome, clinically characterized by progressive and irreversible muscle weakness that compromise the motor function.

It is caused by the absence of the protein dystrophin, due to a deletion in the dystrophin gene, located on chromosome Xp21 [2], leading to a disruption in the mechanism of calcium release. A controlled release of calcium is essential for the muscle fiber contraction and affected cells are susceptible to sarcolemma rupture during contraction. This excessive intake of calcium and inadequate activation of proteases and phospholipases damage the muscle fibers that are replaced by fibro-fatty tissue, featuring a pseudo-hypertrophy of the muscles involved. The absence of dystrophin in the region of synapses in the cerebral cortex also seems to contribute to the cognitive deficits found in patients with DMD [3].

Clinically it is observed progressive muscle weakness, predominantly in the lower limbs, resulting in a characteristic gait pattern (anserine gait) with excessive anterior pelvic tilt, increased hip flexion and abduction, in order to advance the limb; also increased lumbar lordosis, and knee hyperextension in balance are observed. The speed, cadence and stride length of the gait are reduced to improve balance [3].

The children affected by this progressive muscular dystrophy present weakness that interferes with normal functional action. In such case, assessment of the motor function and muscle strength is frequently used to monitor the progress of the disease in this population [4].

According to D'Angelo et al. [5] and Melanda et al. [6], changes in the locomotor system as progressive muscle weakness, muscle fatigue, and development of joint contractures, may alter the gait of these children and lead to loss of this ability between the first and the second decade of life.

Typically in the early stages of DMD, when children are still ambulatory, it is possible to observe a significant reduction in muscle strength. While in advanced stages, when the ability to walk is no longer present (nonambulatory), many functional abilities are equally lost, and motor skills are significantly decreased [7].

Due to this loss of overall functionality, it needs a specific and reliable tool to monitor therapeutic procedures and establish prognosis for recovery. To aim this goal, Berard et al. [8] created the Motor Function Measure (MFM) scale that was validated specifically for neuromuscular diseases by the research group of the Pediatric Rehabilitation L'Escale, Lyon, France. The Brazilian version of this scale was validated in 2008 by Iwabe et al. [9], and it analyzed the functions of the head, trunk, proximal and distal segments of members from a variety of neuromuscular diseases. The version for the Brazilian Portuguese (MFM-P) (Appendix) can be accessed in website http://www.mfm-nmd.org.

The MFM provides a numerical measure of motor skills for patients with neuromuscular diseases. It comprises 32 items, static and dynamic. These items are tested in lying, sitting or standing positions and are divided into three dimensions: Dimension 1 (D1)—standing position and transfers, with 13 items; Dimension 2 (D2)—axial and proximal motor function, with 12 items; Dimension 3 (D3)—distal motor function, with 7 items, 6 of them are related to the upper limb. Each item is graded on a four-point scale, the generic degree is defined by: 0 cannot start the task or cannot maintain the initial position; 1 -partially performs the exercise; 2-partially performs the requested movement or completely realized, but imperfectly (with compensations, insufficient maintenance of time position, slowness, lack of control of movement); 3-fully realized, "usual" exercise with controlled, perfect, objective, and performed with a constant velocity motion. The MFM scale allows the comprehensively evaluation, proximal, distal and axial motor dysfunctions, through evidence into three dimensions, thus being useful instrument for use in a broad spectrum of neuromuscular disorders, ranging from those predominant in girdle to distal ones. The MFM is adapted to patients with walking ability and those with partial or total restriction of movement [7].

Unfortunately there is no curative treatment for DMD at present, but there are palliative managements that can slow down some clinical signs and improving the quality of life and muscle strength, such as the use of corticosteroids and physiotherapy that may prolong the ability to walk [10] [11].

The aim of this study was to analyze the correlation between the gait and motor function in children with DMD by MFM-P scale.

\section{Methods}

A total of 36 medical records with confirmed clinical diagnosis of DMD, attended at the Neuromuscular Dis- 
eases Clinic from Campinas State University (UNICAMP) were reviewed. All patients were male, between 3 and 16 years-old (mean $11.19 \pm 3.53$ ), originating from the countryside and neighborhood of São Paulo and had previous MFM-P scores [7] data. Exclusion criteria comprised no confirmed DMD clinical diagnosis, and association with other diseases or other types of muscular dystrophies.

This retrospective study was approved by the Ethics and Research at Unicamp, by number 532419.

\section{Statistical Analysis}

Data were described and analyzed inferentially with the distribution of the scores of the dimensions (D1-D2-D3) and total score was normalized using the Kolmogorov-Smirnov test. Spearman's coefficient test with a significance level $(\mathrm{p}<0.001)$ was used to verify the correlation between the variables: D1, D2, D3, total score and loss of ambulation.

\section{Results}

The scores of the dimensions and the total score did not show a normal distribution using adjustment Kolmogorov-Smirnov test (p-value $<0.001$ ).

Information regarding the dimensions (D1, D2, D3) and functionality (total score) from each patient were analyzed with values measured in percentages. Low values were indicative of severe functional impairment of the child.

Table 1 shows the correlation between D1 - D2 - D3 scores and functional capacity (total score) from all patients. Values range (in percentage) observed in these patients for D1 were between $0 \%$ and $82.05 \%$, for D2 between $16.66 \%$ and $100.00 \%$, for D3 between $23.80 \%$ and $95.23 \%$ and for functional capacity between $12 \%$ and $88.54 \%$.

From all patients data analyzed, a total of $75 \%$ had scores lower than $41.02 \%$ in D1, 92.36\% in D2, 85.71\% in $\mathrm{D} 3$ and $65.88 \%$ in total score. The average value of $\mathrm{D} 1$ was $18.16 \%(\mathrm{SD}= \pm 25.86)$, D2 $68.82 \%(\mathrm{SD}= \pm 25.74)$, D3 73.01\% ( $\mathrm{SD}= \pm 18.14$ ) and capacity functional of $49.15 \%(\mathrm{SD}= \pm 21.08)$.

Figure 1 shows the scatter plots of functional capacity versus scores (top graphics) and in between dimension scores (bottom graphics). We observed a positive linear association between functional capacity and D2 and D3 scores, but not with D1 scores. When analyzing the values among dimensions we noted a linear relationship between D2 and D3 scores; however no association was observed between D2 and D1 scores. The D1 scores were between $40 \%$ and $80 \%$ when patients had D2 score between $80 \%$ and $100 \%$.

Table 2 shows the values of the total scores versus the dimensions scores when analyzed using the Spearman correlation test with p-values. We observed a positive and statistically significant correlation between dimension and total scores.

Table 3 shows the results analyzed between decreased gait (total score $<70 \%$ and D1 $<40.13 \%$ ) with other dimensions using the Spearman correlation test. We also observed a positive and statistically significant correlation between decrease in gait and dimensions scores ( $\mathrm{p}$-value $<0.001$ ).

\section{Discussion}

The availability of instruments for the functional assessment of patients with neuromuscular diseases such as MFM-P, are a great value as they allow the characterization, assessment and a more accurate follow-up from patients with DMD. Early detection of any motor disturbance, also permit earlier interventions in order to optimize motor function [9] [12]-[14].

Ganea et al. [15] assessed the gait pattern in children with DMD and correlated it with the MFM scale, founding that those with higher dimensions scores, especially in D1, had also higher values in both cadence and gait speed.

Fischmann et al. [16] agreed that the MFM scale is a promising metric instrument to be used in clinical trials to assess the effect of treatments due to the loss of ambulation time in DMD. Their results demonstrated the potential of the MFM scale as a parameter to distinguish the stage of the disease especially regarding to the walking function.

The clinical features of DMD are described since the mid-1800s, initially affecting the muscles of the pelvic girdle and progressing to the neck region, upper abdominal and upper limbs. According to D’Angelo et al. [5] 
Table 1. Descriptive measures of scores D1-D2-D3 and functionality of children with DMD (values in \%).

\begin{tabular}{ccccc}
\hline & D1 & D2 & D3 & Total score \\
\hline Minimum & 0.00 & 16.66 & 23.80 & 12.22 \\
$\mathbf{1}^{\circ}$ Quartile & 0.00 & 51.38 & 65.47 & 33.33 \\
Median & 2.56 & 70.83 & 80.95 & 44.27 \\
Average & 18.16 & 68.82 & 73.01 & 49.15 \\
Deviation & 25.86 & 25.74 & 18.14 & 21.08 \\
Standart & 41.02 & 92.36 & 85.71 & 65.88 \\
$\mathbf{3}^{\circ}$ Quartile & 82.05 & 100.00 & 95.23 & 88.54 \\
Maximum & & & & \\
\hline
\end{tabular}

Table 2. Correlation between the dimensions and total scores values (p values).

\begin{tabular}{cccc}
\hline Scores & Total & D1 & D2 \\
\hline D1 & $0.935^{*}$ & - & - \\
D2 & $0.936^{*}$ & $0.864^{*}$ & - \\
D3 & $0.742^{*}$ & $0.612^{*}$ & $0.682^{*}$ \\
\hline
\end{tabular}

${ }^{*}$ p-value $<0.001$.

Table 3. Correlation of loss of gait with dimensions scores (p values).

\begin{tabular}{ccc}
\hline Scores & Total $<70 \%$ & $\mathrm{D} 1<40 \%$ \\
\hline $\mathbf{D 1}<\mathbf{4 0 \%}$ & $0.853^{*}$ & - \\
D2 & $0.958^{*}$ & $0.834^{*}$ \\
D3 & $0.631^{*}$ & $0.396^{* *}$ \\
\hline
\end{tabular}

${ }^{*}$ p-value $<0.001 ;{ }^{* *}$-value $<0.05$.
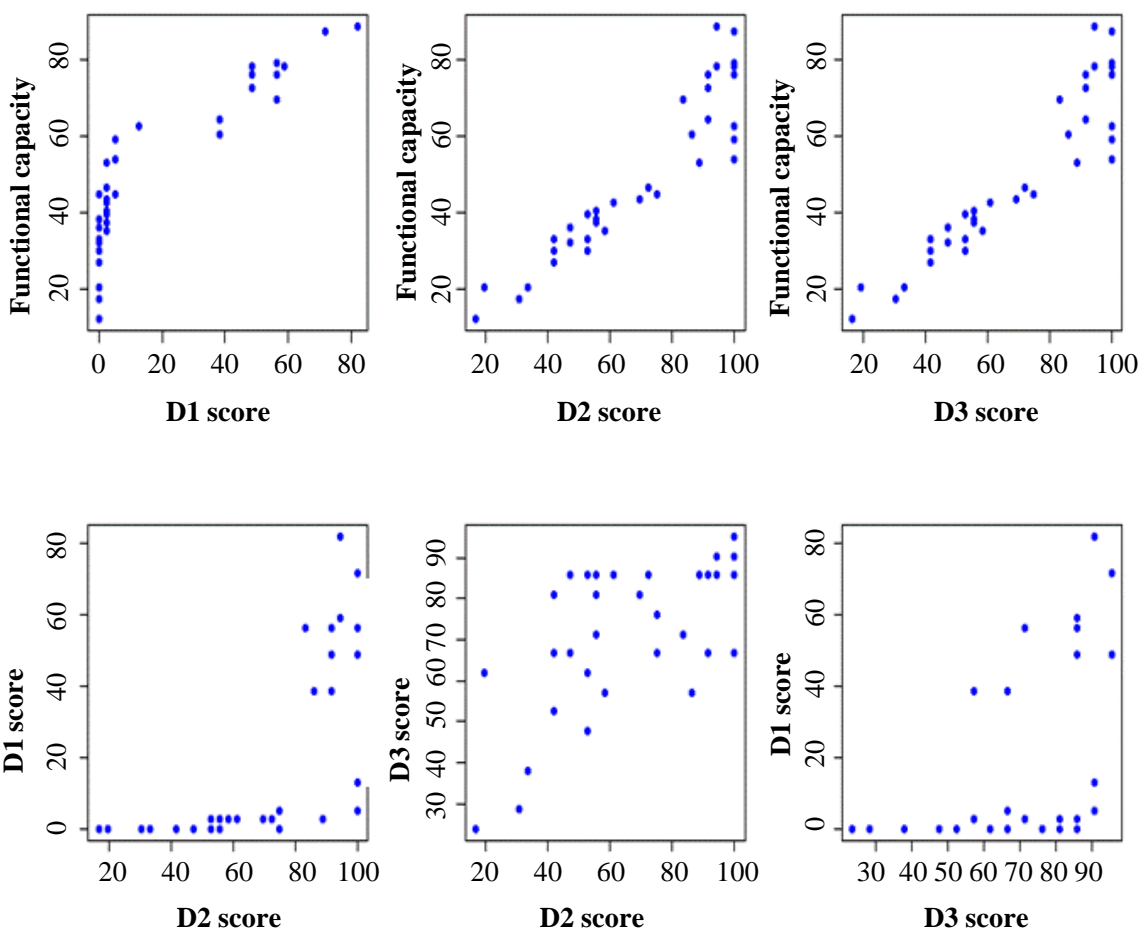

Figure 1. Scatter plot comparing values between scores and functional capacity. 
and Bushby et al. [11] the clinical signs appear first proximal muscles affecting the posture and gait, followed by compromise of the distal, with total loss of this function around 8 - 10 years of age.

Changes in the locomotor system such as progressive muscular weakness, fatigue, and development of joint contractures leads to a postural compensation with difficulty to get up from the ground and especially during gait cycles [17] [18]. These data corroborate our results in which lower scores were observed in the dimension that evaluates standing posture and gait (D1), followed by the proximal involvement (D2) in the majority of analyzed patients.

According to Mc Donald et al. [19], the walking motor activity is crucial for human independence that requires a complex interaction of different muscles from different muscle groups; especially from the proximal portion in order to stabilize the body axis and permit the body and the members to work as a single unit. Another study Bakker et al. [20] reported that musculoskeletal disorders; such as joint deformities and muscle weakness especially proximal segments, undermine the balance as well as the bipedalism and ambulation.

Another study [21] confirmed that loss of strength, especially from the hip extensors, as a predictor of loss of ambulation in DMD. This weakness progressively decreases the ability of a person to perform activities in standing and walking position, developing compensatory movements. Even in the early stages of the disease, it is possible to quantify the difficulties of standing and gait, using effective metric tools.

The execution of more complex tasks during the standing posture requires a sofisticate control of antigravity muscles. The observation of these compensatory movements during functional tasks; such as not being able to get up from the floor or climb up stairs, or the loss of speed, may allow the recognition of important changes in muscle synergies, as well as the prediction of future deficiencies [22].

In this study we were able to observe that the rapid loss of ambulation, as well as the decreased functionality of proximal segments with advancing disease, occurs due to strength deficits related to proximal muscles in the standing posture, observed at the lower values from D1 and D2 scores.

\section{Conclusions}

We concluded that there was a positive correlation between the loss of the ability to walk and functionality in children with DMD where deficits in gait are more evident when the patients have more difficulties in performing activities related to the standing posture and proximal member functions.

We also suggest that increasing the number of patients through a multicentric study will allow us to identify more risk factors that lead to the loss of gait in these patients.

In our study, the use of the MFM-P allowed us to detect different degrees of functional deficits, proving to be an efficient and reliable tool for scientific and clinical use. We consider the MFM-P as an important tool that will allow a better characterization of the severity of the disease, optimizing the physical therapy program to achieve a better result and delaying the progress of the disease.

\section{References}

[1] Fernandes, L.A.Y., Caromano, F.A., Hukuda, M.E., Escorcio, R. and Carvalho, E.V. (2010) Development and Reliability of the Functional Scale Going up and down Stairs for Muscular Dystrophy. Revista Brasileira de Fisioterapia, 14, 518-526. http://dx.doi.org/10.1590/S1413-35552010000600011

[2] Araújo, A.P.Q.C., Deco, M.C., Kloh, B.S., Costa, M.R., Gois, F.V. and Guimarães, F.H.H. (2004) Delay in Diagnosis of Duchenne Muscular Dystrophy. Revista Saúde Materno Infantil, 4, 179-183.

[3] Gomes, A.L.O., Pinto, A.N., Goes, E.R., Hirosue, L.N., Peixoto, B.O., Caromano, F.A. and Blascovi Assis, S.M. (2011) Motor and Functional Performance in Duchenne Muscular Dystrophy: A Case Report. Journal of the Health Sciences Institute, 29, 131-135.

[4] Escorcio, R., Caromano, F.A., Hukuda, M.E. and Fernandes, L.A.Y. (2011) Development of an Evaluation Scale for Sitting and Standing from the Ground for Children with Duchenne Muscular Dystrophy. Journal of Motor Behavior, 43, 37-41.

[5] D’Angelo, M.G., Berti, M., Piccinini, L., Romei, M., Guglieri, M., Bonato, S., Degrate, A., Turconi, A.C. and Bresolin, N. (2009) Gait Pattern in Duchenne Muscular Dystrophy. Gait \& Posture, 29, 36-41. http://dx.doi.org/10.1016/j.gaitpost.2008.06.002

[6] Melanda, A.G., Pauleto, A.C., Knaut, L.A., Ferreira, A.E.K., Iucksch, D.D., Silva, R.M. and Cunha, R.F.M. (2011) Evaluation of Patients with Duchenne Muscular Dystrophy Laboratory Computerized Index March through the Amendment of the March. Revista Brasileira de Ortopedia, 46, 10-13. 
[7] Beenakker, E.A.C., Maurits, N.M., Fock, J.M., Brouwer, O.F. and Hoeven, J.H.V.D. (2005) Functional Ability and Muscle Force in Healthy Children and Ambulant Duchenne Muscular Dystrophy Patients. European Journal of Paediatric Neurology, 9, 387-393. http://dx.doi.org/10.1016/j.ejpn.2005.06.004

[8] Bérard, C., Payan, C. and Hodgkinson, I.J. (2005) The Fermanian Motor Function Measure Scale for Neuromuscular Diseases. Construction and Validation Study. Neuromuscular Disorders, 15, 463-470. http://dx.doi.org/10.1016/j.nmd.2005.03.004

[9] Iwabe, C., Miranda-Pfeilsticker, B.H. and Nucci, A. (2008) Motor Function Measure Scale: English Version and Reliability Analysis. Revista Brasileira de Fisioterapia, 12, 417-424. http://dx.doi.org/10.1590/S1413-35552008000500012

[10] Jeannet, P.Y., Aminian, K., Bloetzer, C., Najafi, B. and Paraschiv-Ionescu, A. (2011) Continuous Monitoring and Quantification of Multiple Parameters of Daily Physical Activity in Ambulatory Duchenne Muscular Dystrophy Patients. European Journal of Paediatric Neurology, 15, 40-47.

[11] Bushby, K., Finkel, R., Birnkrant, D.J., Case, L.E., Clemens, P.R., Cripe, L., et al. (2010) Diagnosis and Management of Duchenne Muscular Dystrophy, Part 1: Diagnosis, and Pharmacological and Psychosocial Management. Lancet Neurology, 9, 77-93. http://dx.doi.org/10.1016/S1474-4422(09)70271-6

[12] Conover, J.W. (1971) Practical Nonparametric Statistics. John Wiley \& Sons, New York, 295-301,309-314.

[13] Vuillerot, C., Girardot, F., Payan, C., Iwaz, J., De Lattre, C. and Berard, C. (2009) Monitoring Changes and Predicting Loss of Ambulation in Duchenne Muscular Dystrophy with the Motor Function Measure. Developmental Medicine \& Child Neurology, 52, 60-65. http://dx.doi.org/10.1111/j.1469-8749.2009.03316.x

[14] Chaustre, D.M. and Willington, C.S. (2011) Duchenne Muscular Dystrophy. Prospects of Rehabilitation. Review Article. Rev. Fac Med, 19, 37-44.

[15] Ganea, R., Jeannet, P.Y., Ionescu, A.P., Goemans, N.M., Piot, C., Den Hauwe, M.V. and Aminian, K. (2012) Gait Assessment in Children with Duchenne Muscular Dystrophy during Long-Distance Walking. Journal of Child Neurology, 27, 30-38. http://dx.doi.org/10.1177/0883073811413581

[16] Fischmann, A., Hafner, P., Gloor, M., Schmid, M., Klein, A., Pohlman, U., et al. (2013) Quantitative MRI and Loss of Free Ambulation in Duchenne Muscular Dystrophy. Journal of Neurology, 260, 969-974. http://dx.doi.org/10.1007/s00415-012-6733-X

[17] Da Silva, E.C., Machado, D.L., Resende, M.B.D., Silva, R.F., Zanoteli, E. and Reed, U.C. (2012) Scale Measure of Motor Function, Steroid Therapy, and Patients with Duchenne Muscular Dystrophy. Arquivos de Neuro-Psiquiatria, 70, 191-195.

[18] Santos, N.M., Rao, M.M., Terni, A., Hayashi, M.C.B., Fávero, F.M., Tables, A.A.J., et al. (2006) Clinical and Functional Profile of Patients with Duchenne Muscular Dystrophy Assisted in Brazilian Muscular Dystrophy Association (ABDIM). Reviews in the Neurosciences, 14, 15-22.

[19] McDonald, C.M., Henricson, E.K., Han, J.J., Abresch, R.T., Nicorici, A., Elfring, G.L., Atkinson, L., Reha, A., Hirawat, S. and Miller, L.L. (2009) The 6-Minute Walk Test as a New Outcome Measure in Duchenne Muscular Dystrophy. PTC Therapeutics, 100 Corporate Court, South Plainfield, New Jersey. www.interscience.wiley.com

[20] Bakker, J.P.J., de Groot, I.J.M., Beelen, A. and Lankhorst, G.J. (2002) Predictive Factors of Cessation of Ambulation in Patients with Duchenne Muscular Dystrophy. American Journal of Physical Medicine \& Rehabilitation, 81, 906-912. http://dx.doi.org/10.1097/00002060-200212000-00004

[21] Zanoteli, E. (2014) Predicting the Loss of Ambulation in Duchenne Muscular Dystrophy. Arquivos de Neuro-Psiquiatria, 72, 1-2. http://dx.doi.org/10.1590/0004-282X20130243

[22] Martini, J., Voos, M.C., Hukuda, M.E., Resende, M.B.D. and Caromano, F.A. (2014) Compensatory Movements during Functional Activities in Ambulatory Children with Duchenne Muscular Dystrophy. Arquivos de Neuro-Psiquiatria, 72, 5-11. http://dx.doi.org/10.1590/0004-282X20130196

\section{Appendix}

The MFM manual in France, English, Portuguese (Iwabe et al., 2008) is available in website www.mfm-nmd.org. 
Scientific Research Publishing (SCIRP) is one of the largest Open Access journal publishers. It is currently publishing more than 200 open access, online, peer-reviewed journals covering a wide range of academic disciplines. SCIRP serves the worldwide academic communities and contributes to the progress and application of science with its publication.

Other selected journals from SCIRP are listed as below. Submit your manuscript to us via either submit@scirp.org or Online Submission Portal.
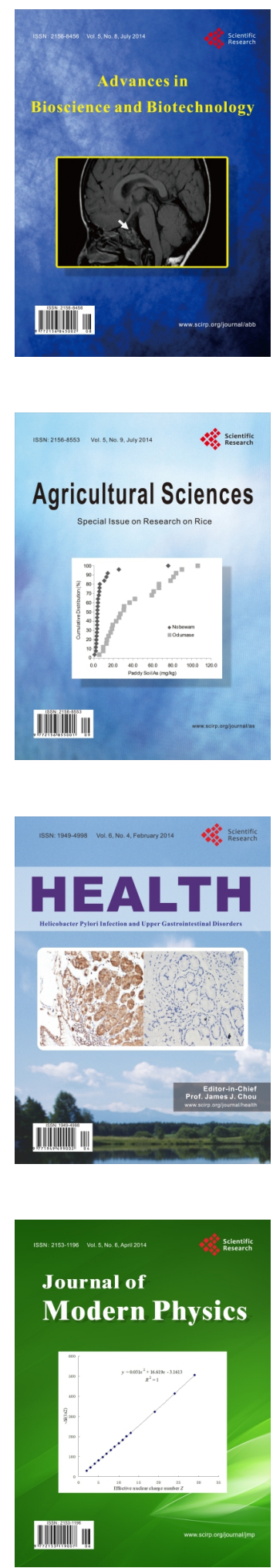
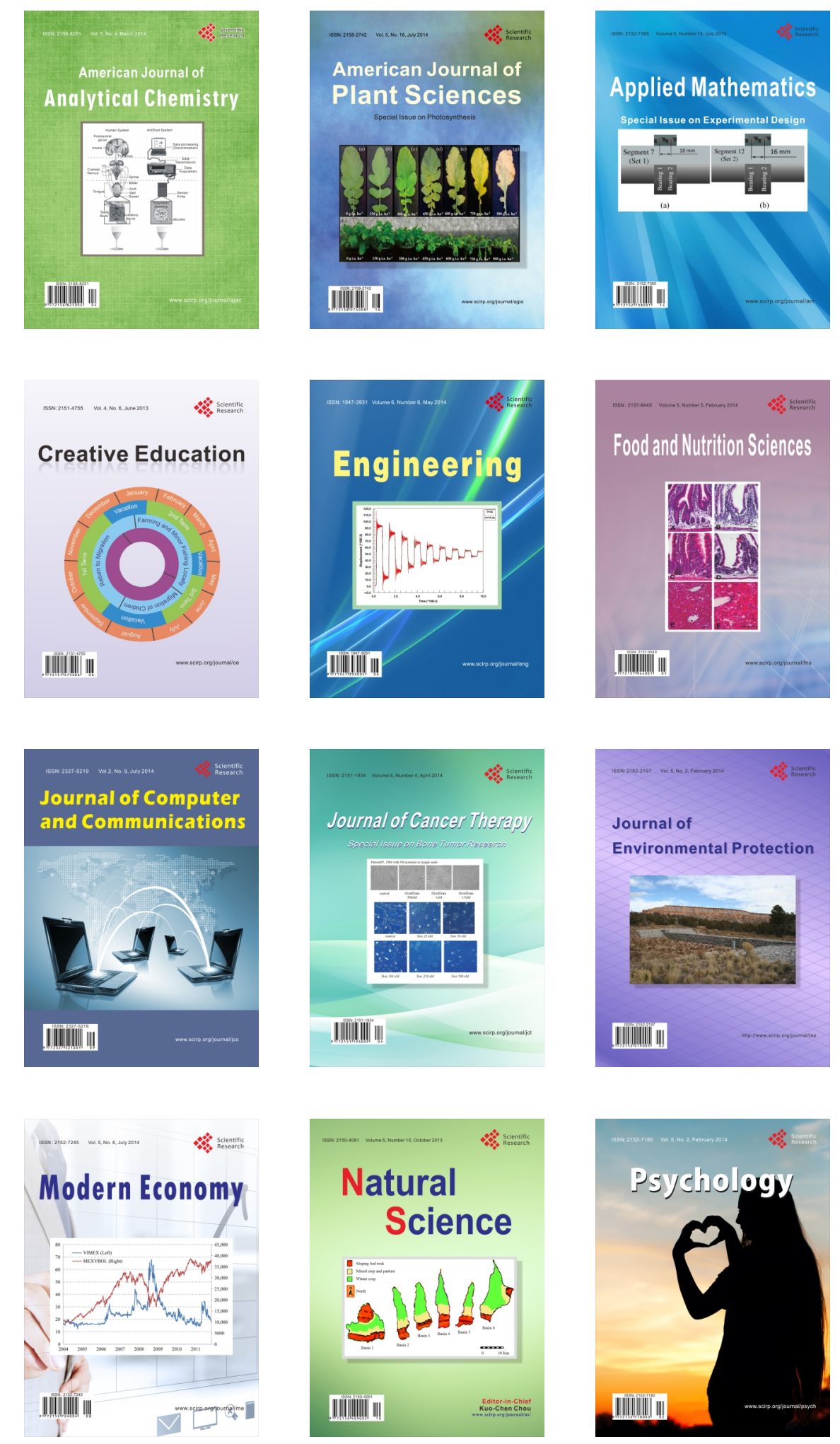